\title{
$\geqslant$

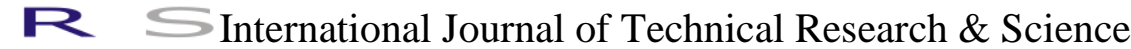 \\ ISOLATION AND IDENTIFICATION OF BACTERIA FROM WOUND INFECTION AND THEIR ANTIBIOGRAM
}

\author{
M. L. Mohammed Kaleem Arshan ${ }^{1}$, Ankit Jurla and Sneha Khadse ${ }^{2}$ \\ E-Mail Id: arshanml@yahoo.com \\ ${ }^{1}$ Department of Biotechnology, Islamiah College (Autonomous) Vaniyambadi \\ ${ }_{2}^{2}$ Department of Microbiology, Rashtrasant Tukdoji Maharaj Nagpur University, Nagpur
}

\begin{abstract}
Surgical site infection (SSI) continues to be a major source of morbidity and mortality in developing countries despite recent advances in aseptic techniques. Therefore, effective treatment and management of wound infections in hospital and community setting will require detailed epidemiological knowledge of the infecting bacterial pathogens and their antibiogram unusual to the environment. Based on this information, we examined the frequency and antibiogram of bacterial pathogens isolated from wound infection cases seen at Nagpur Government Hospital over the study period. Bacterial growth was observed in the vast majority of wound. Most of the bacteria isolated were Gram-negative. Staphylococcus aureus was the most common isolated organism followed by other Klebsiella pneumoniae and Pseudomonas aeruginosa. Staphylococcus aureus and Pseudomonas aeruginosa was the most common isolated bacteria in all patients whereas Klebsiella pneumoniae was the most common isolated bacteria in young patients. Gram-positive isolates were resistant to ampicillin, penicillin, colistin and norfloxacin, while Gram-negative isolates were resistant to penicillin, ampicillin, tetracycline, Tobramycin and Cefotaxime.
\end{abstract}

\section{INTRODUCTION}

Bacterial infections of wounds are among the leading causes of morbidity and mortality throughout the world and are regarded as one of the most common nosocomial infections. According to a team led by World Health Organization researchers found developing countries had much higher infection rates than the developed world it is said "poor nation face: greater hospital infection burden" Wound infection results from microbes thriving in the surgical site because of poor preoperative preparation, wound contamination, improper antibiotic selection, or the lack of ability of an immunocompromised patient to fight against infection. Contamination of the wound is present to some extent in all incisions. A setback in recovery such as malnutrition, cardiac failure, or decreased oxygen to the tissues will deteriorate the individual and allow the infection to take hold. [1, 2, 3]. Common bacterial pathogens associated with wound infection include Staphylococcus aureus, Escherichia coli, Pseudomonas aeruginosa, Klebsiella pneumoniae, Streptococcus pyogenes, Proteus species, Streptococcus species, and Enterococcus species. Identification of bacterial pathogens with information of their antimicrobial susceptibility of wounds can help clinicians to select appropriate medication procedure as in providing them with suitable antibiotic for empirical treatment.

\section{MATERIAL AND METHOD}

A total of 10 pus sample were collected from Nagpur Government Hospital over a period of six months (October 2015 to March 2016) were analyzed. The pus samples were collected from infected wounded patients were from both sexes and all age groups.

\subsection{Sample Collection}

The pus and serous fluid samples from the wounds were collected with the help of two sterile moist swab sticks from the patients, under all aseptic conditions.

\subsection{Transportation and Storage}

Swab sticks were transported in $2 \mathrm{ml}$ normal saline \& BHI broth to laboratory as early as possible. In case of any delay the sample were refrigerated.

\subsection{Processing of Sample}

Two sterile swab sticks were used to collect the pus samples. 1st swab stick was used for gram staining and II $^{\text {nd }}$ swab stick was used for culture. Direct smear with gram stain were screened for the presence of microbial flora. II ${ }^{\text {nd }}$ swab was inoculated on Nutrient agar (NA); Mannitol salt agar (MSA); Eosine Methylene Blue (EMB); Pseudomonas Isolation agar (PIA); Xavier lindon Dawson agar (XLD); Endo agar (Endo); Cystine lactose Electrolyte-deficient agar (CLED); MacConkey Agar (MAC); Baird Parker Agar(BPA) and were cultured for 24-48 hours at $37^{\circ} \mathrm{c}$, followed by the identification of the isolates based on their cultural characteristics and morphology DOI Number: https://doi.org/10.30780/IJTRS.V05.I04.004

pg. 21

Www.ijtrs.com

www.ijtrs.org 


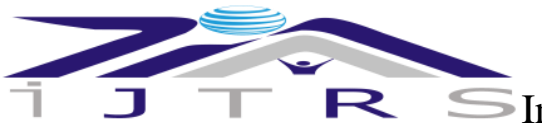

\section{International Journal of Technical Research \& Science}

with their biochemical reactions (like IMViC Pattern, catalase, coagulase, oxidase \& urease test. All the isolates were tested for antimicrobial susceptibility by Kirby Bauer disk diffusion technique on Muller Hinton Agar. Antibiotics used for susceptibility testing were: Ceftotaxime $-30 \mathrm{mcg}$; Tobramycine-10 mcg; Levofloxacine-5 mcg; Ampicillin-2 mcg; Penicillin-G-10 units; Tetracycline-30 mcg; Choloramphenicol-30 mcg; Norfloxacin-10 mcg; Ticarcylin-75 mcg; Meropenem-10 mcg.

\section{RESULT AND DISCUSSION}

A total of 10 study participants with wound infection were included in the study. Among these, 6 (60\%) were males and $4(40 \%)$ were females with the age range of 15 to 65 years. The majority of the study participants were lived in rural areas, of all were unable to read and write Of the 10 wound specimens examined, 3 different bacterial pathogens such as Staphylococcus aureus, Klebsiella pneumoniae and Pseudomonas aeruginosa were isolated, 2 (75\%) gram-negative bacteria and 1 (25\%) gram-positive bacteria. The antimicrobial susceptibility patterns of the Gram-positive and Gram-negative bacterial isolates were presented in Tables 3 and 4, respectively. The predominant isolate, S. aureus, revealed high level of resistance to ampicillin, penicillin, colistin, norfloxacin; and it was also found to be sensitive to ceftotaxime, meropenem, tetracycline, chloramphenicol, Ticarcillin and tobramycin. The second predominant Gram-negative isolate, Klebsiella pneumoniae, showed also high level of resistance to ampicillin, penicillin, colistin, norfloxacin and tetracycline, it was sensitive to ceftotaxime, meropenem, chloramphenicol and Ticarcillin but it was intermediate to tobramycin. Pseudomonas aeruginosa isolates were sensitive to chloramphenicol and Ticarcillin. It was highly resistant to ceftotaxime, meropenem, ampicillin, penicillin, colistin, norfloxacin and tetracycline, but it was intermediate to tobramycin. According to the previous studies males were predominant over females having surgical site infection. Sahu et.al recorded higher infection in males as compared to females [4]. Hernandez et.al reported (65.6\%) males and (34.4\%) females among the SSI patients [5]. In contrast present study reveals that males (60\%) and females (40\%) have significant difference. Anusha et al. reported (65.34\%) gram -ve and (34.66\%) gram +ve whereas in contrast to this study Aizza Zafar et al. concluded that gram positive and gram negative was found to be almost equal (49.54\%) and (50.45\%) respectively. our study shows gram negative (75\%) and gram positive $(25 \%)$.[6,7]

In general, Staphylococcus aureus was the most common bacteria isolated in this study. This is a finding consistent with most studies done across the world [10, 11, 12]. S. aureus are normal flora of the skin and anterior nares, therefore they can easily contaminate wounds and cause infections. Moreover, S. aureus are known to have a vast number of virulence factors that increase their ability to cause infections when compared to other bacteria. Our findings are contrary to the study conducted in a similar setting where Pseudomonas aeruginosa was the common isolate in SSI. These variations could be attributed to several factors including the nature of the surgical site itself, the wound site, the type of prophylactic antibiotics used for infections prevention, the level of nursing care given and the measures taken to prevent nosocomial infections $[9,10]$. Antimicrobial susceptibility testing of the bacterial isolates was done by Kirby Bauer disc diffusion method (Table 1). Most Gram-positive isolates were sensitive to ceftotaxime, meropenem, tetracycline, chloramphenicol, Ticarcillin and tobramycin. The majority of the isolates from infected wounds are known to be resistant to ampicillin, penicillin, colistin and norfloxacin.

\section{CONCLUSION}

The isolation rate of bacterial pathogens was high. The predominant isolates were Staphylococcus aureus, Klebsiella pneumoniae and Pseudomonas aeruginosa. The present findings show higher rates of isolation of Gram-negative wound pathogens compared to Gram-positives. Depending on the site of wound infection and clinical symptoms, the role of the microbiology laboratory is to determine the clinically significant isolates, perform antimicrobial susceptibility testing, and subsequently provide guidance on the most appropriate treatment. This will help in successful wound management and will also assist in the control of antibiotic usage and hence curtail the spread of antibiotic-resistant bacteria.

\section{REFERENCES}

[1] Matthew. S Dryden. (2009). Elsevier international Journal of antimicrobial agents. 52-57.

[2] Owings, M. F., and L. J. Kozak. (1998). "Ambulatory and Inpatient Procedures in the United States, 1996."Vital health statistics" 139 Nov; 1-119.

[3] Sabiston. Text book of surgery: the biological basis of modern surgical practice Beauchamp eversmattox (16th Ed) surgical complications, 199.

[4] Sohn AH, Pervez FM, Vu T, Hai HH, Bich NN, Le Thu TA. (2002). Prevalence of surgical-site infections and patterns of antimicrobial use in a large tertiary care hospital in Ho Chi Minh City, Vietnam. Infect Control Hosp Epidemiol; 23: 382-87.

DOI Number: https://doi.org/10.30780/IJTRS.V05.I04.004

pg. 22

WWw.ijtrs.com

www.ijtrs.org

Paper Id: IJTRS-V5-I4-026 
J $\mathbb{R} \leqq$ International Journal of Technical Research \& Science

[5] Anusha S, Vijaya LD, Pallavi K, Manna PK, Mohanta GP, Manavalan R. (2010). An Epidemiological Study of Surgical Wound Infections in a Surgical unit of Tertiary care Teaching Hospital Indian Journal of Pharmacy Practice Volume 3 Issue 4 Oct - Dec

[6] Hernandez K, Ramos E, Seas C, Henostroza G, Gotuzzo E. (2005). Incidence of and risk factors for surgicalsite infections in a Peruvian hospital. Infect Control HospEpidemiol; 26(5): 473-7.

[7] Anvikar AR, Deshmukh AB, Karyakarte RP, Dample AS, Patwardhan NS, Malik AK. (1999). A one year prospective study of 3,280 surgical wounds. Indian J Med Microbiol; 17: 129-32.

[8] Zafar A, Anwar N AND Ejaz H. (2008). Bacteriology of infected wounds - A study conductedat children hospital lahore .Biomedical Vol.24 Jan. - Jun. /Bio-O (A).

[9] Manyahi J. (2012). Bacteriological spectrum of post operative wound infections and their antibiogram in a Tertiary Hospital, Dar Es Salaam, Tanzania. Master thesis in Medicine (Microbiology and Immunology). Muhimbili University of Health and Allied Sciences.

[10] Shriyan A, Sheetal R, Nayak N. (2010). Aerobic micro-organism in post-operative wound infection and their antimicrobial susceptibility patterns. J Clin Diagn Res.3: 2208-16.

[11] Taiwo S, Okesina A, Onile B. (2002). In vitro antimicrobial susceptibility pattern of bacteria isolated from infected wounds at the University of Illorine teaching Hospital. Afr J Exp Exp Microbiol. 3:13-6.

[12] Ahmed MI. (2012). Prevalence of nosocomial wound infection among postoperative patients and antibiotics patterns at teaching hospital in Sudan. N Am J Med Sci. 4:29-34.

Table-1 Antibiotic Susceptibility Testing Of Pathogens

\begin{tabular}{|c|l|l|c|c|c|}
\hline \multirow{2}{*}{ S. No } & \multicolumn{1}{|}{ Antibiotics } & $\begin{array}{c}\text { Concentration } \\
\text { of antibiotics }\end{array}$ & $\begin{array}{c}\text { Staphylococcus } \\
\text { aureus }\end{array}$ & $\begin{array}{c}\text { Klebsiella } \\
\text { pneumonia }\end{array}$ & $\begin{array}{c}\text { Pseudomonas } \\
\text { aeroginosa }\end{array}$ \\
\hline 1 & Ceftotaxime & $30 \mathrm{mcg}$ & Sensitive & Sensitive & Resistant \\
\hline 2 & Meropenem & $10 \mathrm{mcg}$ & Sensitive & Sensitive & Resistant \\
\hline 3 & Colistin & $10 \mathrm{mcg}$ & Resistant & Resistant & Resistant \\
\hline 4 & Tetracycline & $30 \mathrm{mcg}$ & Sensitive & Resistant & Resistant \\
\hline 5 & Ampicillin & $10 \mathrm{mcg}$ & Resistant & Resistant & Resistant \\
\hline 6 & Chloramphenicol & $30 \mathrm{mcg}$ & Sensitive & Sensitive & Sensitive \\
\hline 7 & Penicillin $-\mathrm{G}$ & $10 \mathrm{mcg}$ & Sensitive & Resistant & Resistant \\
\hline 8 & Norfloxacin & $10 \mathrm{mcg}$ & Sensitive & Resistant & Resistant \\
\hline 9 & Ticarcillin & $75 \mathrm{mcg}$ & Sensitive & Sensitive & Sensitive \\
\hline 10 & Tobramycin & $10 \mathrm{mcg}$ & Sensitive & Intermediate & Intermediate \\
\hline
\end{tabular}

